\title{
Gallic acid, a phenolic compound, exerts anti-angiogenic effects via the PTEN/AKT/HIF-1 $\alpha /$ VEGF signaling pathway in ovarian cancer cells
}

\author{
ZHIPING HE ${ }^{1,2}$, ALLEN Y. CHEN ${ }^{3}$, YON ROJANASAKUL ${ }^{3}$, GARY O. RANKIN ${ }^{4}$ and YI CHARLIE CHEN RH $^{1,2}$ \\ ${ }^{1}$ Key Laboratory for Quality Improvement of Agricultural Products of Zhejiang Province, College of Agriculture \\ and Food Science, Zhejiang A \& F University, Lin'an, Zhejiang 311300, P.R. China; ${ }^{2}$ College of Science, Technology \\ and Mathematics, Alderson Broaddus University, Philippi, WV 26416; ${ }^{3}$ Department of Pharmaceutical Science, \\ West Virginia University, Morgantown, WV 26506; ${ }^{4}$ Department of Pharmacology, Physiology and Toxicology, \\ Joan C. Edwards School of Medicine, Marshall University, Huntington, WV 25755, USA
}

Received July 12, 2015; Accepted July 23, 2015

DOI: $10.3892 /$ or.2015.4354

\begin{abstract}
Gallic acid (GA), a polyphenol, is widely found in numerous fruits and vegetables, particularly in hickory nuts. In the present study, we found that gallic acid, a natural phenolic compound isolated from fruits and vegetables, had a more potent growth inhibitory effect on two ovarian cancer cell lines, OVCAR-3 and A2780/CP70, than the effect on a normal ovarian cell line, IOSE-364. These results demonstrated that GA selectively inhibits the growth of cancer cells. Gene expression was examined by ELISA and western blot analysis, and gene pathways were examined by luciferase assay. It was found that GA inhibited VEGF secretion and suppressed in vitro angiogenesis in a concentration-dependent manner. GA downregulated AKT phosphorylation as well as HIF-1 $\alpha$ expression but promoted PTEN expression. The luciferase assay results suggest that the PTEN/AKT/HIF-1 $\alpha$ pathway accounts for the inhibitory effect of GA on VEGF expression and in vitro angiogenesis. These findings provide strong support for the high potential of GA in the prevention and therapy of ovarian cancer.
\end{abstract}

\section{Introduction}

Epidemiological studies have demonstrated that diets rich in fruits and vegetables have a chemopreventive effect on the development of cancer. It has been reported that phenolic compounds, a large family of natural compounds, abundant in fruits and vegetables, have been associated with a possible reduced risk of prostate cancer (1), breast cancer (2), liver

Correspondence to: Dr Yi Charlie Chen, College of Science, Technology and Mathematics, Alderson Broaddus University, 101 College Hill Drive, Philippi, WV 26416, USA

E-mail: chenyc@ab.edu

Key words: ovarian cancer, angiogenesis, VEGF, HIF-1 $\alpha$, gallic acid cancer (3) and cervical cancer (4). The potential application of phenolic compounds in the development of therapeutic agents for cancer treatment and for their use as valuable additive or nutritional supplements to prevent cancer risk has gained increasing importance, and research in this field is currently expanding (5-7).

Ovarian cancer is one of the leading causes of cancerrelated mortality in women in developed areas (8). In 2015, an estimated 21,290 new cases and 14,180 deaths due to ovarian cancer occurred in the USA (9). Unfortunately, the overall survival rate at 5 years is only $50 \%$, which has not significantly improved in the past 30 years (10). Even though the majority of women have successful initial therapy, the low rate of survival is due to eventual recurrence and succumbing to the disease. The treatment for ovarian cancer is still unsatisfactory, and new treatments for patients with recurrent ovarian cancer who are incurable with current management are needed. Another challenge is that more than $70 \%$ of women present with advanced stage disease (11). Symptoms of the disease generally do not present themselves until after the cancer has metastasized from the ovaries to the surfaces of the peritoneal cavity. Once metastasis has occurred, surgical removal of all lesions is no longer possible, making ovarian cancer extremely difficult to combat. The remaining first-line treatment option is chemotherapy.

Cytoreductive surgery followed by platinum and taxane-based combination chemotherapy is currently the standard treatment for ovarian cancer (12). Ovarian cancer is one of the most sensitive solid tumors, with objective responses ranging from 60 to $80 \%$ to chemotherapy even in patients with advanced stage disease. However, most patients ultimately recur and develop resistance to chemotherapy. Resistance to chemotherapy presents a major obstacle to improving the prognosis of patients with ovarian cancer. The response rate to current second-line or third-line (after interim non-platinum therapy) chemotherapy is $<33 \%$ due to the rise in resistance to these drugs $(13,14)$. Therefore, selecting new chemicals as cancer therapeutics from natural compounds is still crucial for ovarian cancer research. Finding new natural compounds that 
match or exceed the effects of common chemical drugs, or are able to be given in combination with cisplatin to overcome resistance is of great significance (15). Our previous studies have shown that phenolic compounds are effective inhibitors of cell growth and vascular endothelial growth factor (VEGF) expression in ovarian cancer cells (16-18).

Gallic acid (3,4,5-trihydroxybenzoic acid, GA), a predominant polyphenol, is an endogenous plant polyphenol abundantly found in tea, grapes, berries and other fruits as well as in wine. GA has been shown to exhibit a variety of pharmacological and biological properties, including antibacterial, antiviral, and antitumor activities in many human cancer cell lines. Its anticancer activity has been reported in oral (19), lung (20), pancreatic (21), glioma (22) and cervical cancer cells (23).

In our previous experiments, we found that GA has the greatest inhibitory activity on human ovarian cancer cells among eight natural phenolic compounds from traditional Chinese medicine (24). However, the molecular mechanisms underlying the anti-angiogenic effects of GA on ovarian cancer have not been discussed in detail to date. In the present study, the inhibitory effect on cell proliferation, in vitro angiogenesis and VEGF expression by GA on human ovarian cancer cell lines was examined. In particular, the mechanism of GA-induced anti-angiogenesis in OVCAR-3 cells was further studied.

\section{Materials and methods}

Cell culture and treatment. Ovarian cancer cell line OVCAR-3 was provided by Dr BingHua Jiang of West Virginia University. IOSE-364, normal ovarian surface epithelial cells from healthy women, but immortalized with SV40 T/t, were courtesy of Dr Auersperg of the University of British Columbia, Canada. All cells were maintained in RPMI-1640 medium (Sigma) supplemented with $10 \%$ US-qualified fetal bovine serum (Invitrogen, Grand Island, NY, USA) in a cell culture incubator with $5 \% \mathrm{CO}_{2}$ at $37^{\circ} \mathrm{C}$. A stock solution of GA (Sigma) was prepared in dimethyl sulfoxide (DMSO) at $100 \mathrm{mM}$ and stored at $-20^{\circ} \mathrm{C}$. Different concentrations of GA were prepared in RPMI-1640 medium for cell treatments, and DMSO was included in the preparations to ensure equal concentrations of DMSO in each treatment.

Cell viability assay. To measure cell viability, cells were seeded in 96-well plates at a density of $1 \times 10^{4} /$ well and allowed to recover, attach to the substrate, and grown to log phase overnight. After incubation $37^{\circ} \mathrm{C}$, the culture medium was removed and incubated with different concentrations of GA for $24 \mathrm{~h}$. Each treatment was performed in triplicate. After treatment, the cells were washed twice with phosphate-buffered saline (PBS), introduced to $100 \mu \mathrm{l}$ freshly prepared AQueous One Solution (MTS tetrazolium compound) (Promega, Madison, WI, USA) in medium, and incubated for $1 \mathrm{~h}$ at $37^{\circ} \mathrm{C}$. The OD values, at $490 \mathrm{~nm}$, were measured by an enzyme-linked immunosorbent assay (ELISA) plate reader (Bio-Tek Instruments, Winooski, VT, USA). Cell viability was expressed as a percentage of the control.

VEGF protein quantification. The effect of GA on VEGF protein secretion was analyzed by ELISA with a Quantikine Human VEGF Immunoassay kit (R\&D Systems, Minneapolis,
MN, USA), targeting VEGF165 in the cell culture supernatant. Cells $\left(6 \times 10^{5}\right)$ were seeded in $60-\mathrm{mm}$ cell culture dishes and allowed to attach to the substrate and grow for $16 \mathrm{~h}$ at $37^{\circ} \mathrm{C}$ before treatment with various concentrations of GA for $24 \mathrm{~h}$. Culture supernatants were collected for the VEGF assay. The inhibition of VEGF protein secretion was expressed as a percentage of the control. Cell lysates were also assayed for total protein levels using the BCA protein assay kit (Pierce, Rockford, IL, USA) to adjust VEGF levels.

In vitro angiogenesis assay. OVCAR-3 cancer cells were seeded in $60-\mathrm{mm}$ cell culture dishes at $6 \times 10^{5}$ cells/dish and incubated overnight. Cells were then treated with $4 \mathrm{ml}$ serum-free medium containing $0,5,10$, or $20 \mu \mathrm{M}$ GA for $24 \mathrm{~h}$ and collected for the in vitro angiogenesis assay. Growth factor-reduced Matrigel (BD Biosciences, San Jose, CA, USA) was transferred into 96 -well plates at $50 \mu \mathrm{l} /$ well and incubated at $37^{\circ} \mathrm{C}$ for $1 \mathrm{~h}$ to gel. Human umbilical vein endothelial cells (HUVECs) were harvested in PBS, counted, and seeded onto the Matrigel beds at $2 \times 10^{4}$ cells/ $90 \mu 1$ PBS. Thereafter, volumes of $10 \mu 1$ of the collected conditioned media were added to each well. The system was incubated at $37^{\circ} \mathrm{C}$ for $8 \mathrm{~h}$, and tube formation was visualized under a microscope with images captured for comparison.

Western blot analysis. OVCAR-3 cancer cells were seeded and incubated overnight before treatment with GA. After a double wash with cold PBS, the cells were harvested with M-PER Mammalian Protein Extraction reagent supplemented with Halt protease and phosphatase inhibitor (both from Pierce), and total protein levels were assayed with the BCA protein assay kit. Cell lysates (50 $\mu \mathrm{g}$ total protein) were separated by SDS-PAGE and blotted onto a nitrocellulose membrane with a Mini-Protean 3 system (Bio-Rad, Hercules, CA, USA). For immunodetection, antibodies against HIF-1 $\alpha$, HIF-1 $\beta$, AKT, p-AKT, PTEN and GAPDH (Santa Cruz Biotechnology, Santa Cruz, CA, USA) were applied, and signals were visualized with phycoerythrin-conjugated anti-mouse IgG secondary antibodies, SuperSignal West Pico Substrate, and X-ray film (Pierce). Protein bands were quantitated with NIH ImageJ software and normalized by GAPDH bands for analysis.

Transient transfection and luciferase assay. OVCAR-3 cancer cells $\left(1 \times 10^{4}\right.$ cells/well) were seeded onto 96-well plates and incubated overnight. For transfection with hypoxia-inducible factor $1 \alpha$ (HIF-1 $\alpha$ ) plasmids (Addgene, Cambridge, MA, USA), cells were transfected with VEGF luciferase reporter $(0.05 \mu \mathrm{g})$ and HIF- $1 \alpha$ plasmids $(0,0.0625,0.125$ and $0.25 \mu \mathrm{g})$ or SR-a (as vehicle) plasmids using $0.6 \mu 1$ of jetPRIME reagent (VWR, West Chester, PA, USA) for $4 \mathrm{~h}$. For transfection with mAkt plasmids (Addgene), the cells were transfected with HIF-1 $\alpha$ or VEGF luciferase reporter $(0.05 \mu \mathrm{g})$ and mAkt $(0$, 0.0625 , and $0.125 \mu \mathrm{g}$ ) or the SR-a plasmids using $0.6 \mu \mathrm{l}$ of jetPRIME reagent for $4 \mathrm{~h}$. After transfection, all the cells were treated with or without GA $(5 \mu \mathrm{M})$ for $16 \mathrm{~h}$. The cells were harvested and analyzed for luciferase activity and total protein levels using a BCA protein assay kit, and the activities of VEGF reporter or the HIF-1 $\alpha$ reporter were normalized to corresponding total protein levels for statistical analysis. The experiments were conducted 3-8 times. 


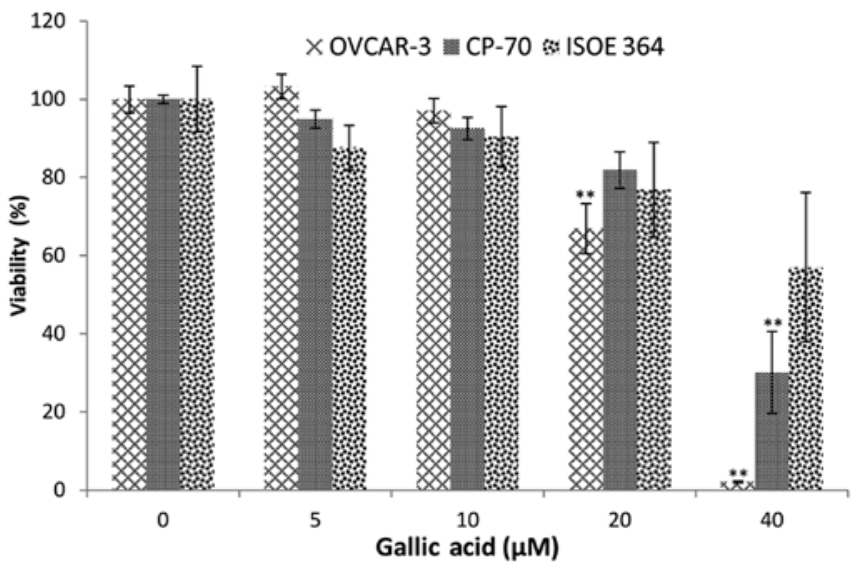

Figure 1. Gallic acid (GA) inhibits cell proliferation in OVCAR-3 and A2780/CP70 ovarian cancer cells and ISOE 364 ovarian normal cells in a dose-dependent manner. Data represents means \pm SE from 4 independent experiments. All data were analyzed by one-way ANOVA analysis followed by Dunnett's test. ${ }^{\text {}} \mathrm{P}<0.05$ as compared to the control; ${ }^{* *} \mathrm{P}<0.01$ as compared to the control.

Statistical analysis. One-way ANOVA followed by Dunnett's test or by the Student's t-test was applied to compare the effects between chemical treatments. A p-value of $<0.05$ was considered as indicative of a statistically significant result.

\section{Results and Discussion}

GA inhibits cell proliferation and VEGF secretion dose-dependently in an ovarian cancer cell line. Phenolic compounds, a large family of natural compounds with phenolic hydroxyls found in plants, fruits, vegetables and teas, have long been regarded as significant secondary metabolites for their chemopreventive and chemotherapeutic effects in cancer $(25,26)$. In our previous experiments, eight natural phenolic compounds from traditional Chinese medicine were compared for their anti-proliferative effects on an ovarian cancer cell line at concentrations of 20 and $40 \mu \mathrm{M}$ using a cell viability assay. We found that GA had the greatest inhibitory activity among these phenolic compounds (24). Therefore, GA was selected for subsequent experiments. Yet, we needed to clarify the appropriate dosage of GA needed to exert significant effects and to determine the relative cytotoxic effects on ovarian cancer cell lines compared to normal ovarian cells. In the present study, we further examined the suppression of cell viability after treatment with varying concentrations of GA $(0,5,10,20$ and $40 \mu \mathrm{M})$ in ovarian cancer cell lines (OVCAR-3, A2780/CP70) and in a normal ovarian cell line (ISOE-364).

As shown in Fig. 1, an overall inhibitory effect of GA on ovarian cancer cell lines and the normal ovarian cell line was tested. A2780/CP70 cell viability was significantly inhibited to $30.10 \%$ at $40 \mu \mathrm{M}$ GA treatment. The inhibitory effect on OVCAR-3 cells was much higher than that on the A2780/CP70 cells. OVCAR-3 cell viability was inhibited to 66.86 and $2.11 \%$ by 20 and $40 \mu \mathrm{M}$ GA treatment, respectively. Compared to the inhibitory effect of cisplatin at $20 \mu \mathrm{M}$ (16), the lower cell viabilities demonstrate that GA has high potential in the prevention and therapy of ovarian cancer.

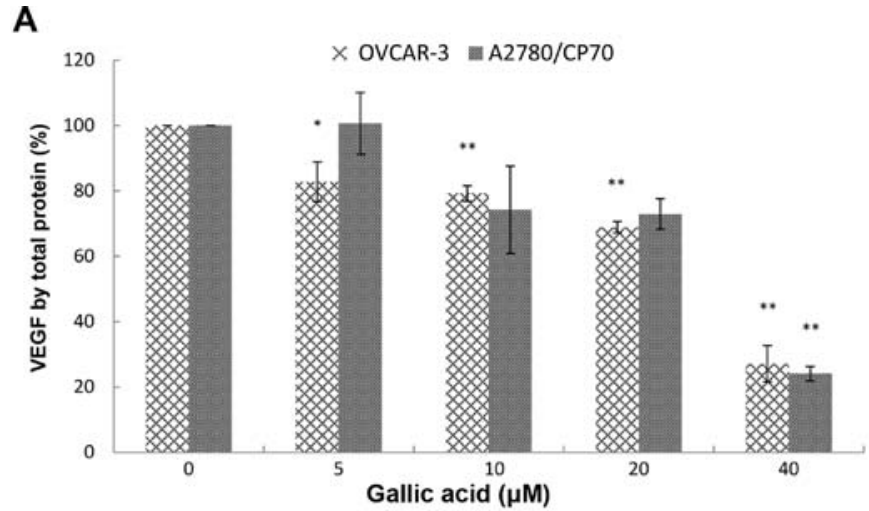

B

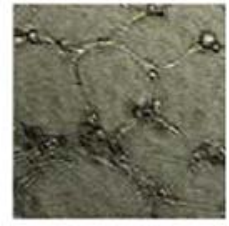

$0 \mu \mathrm{M}$

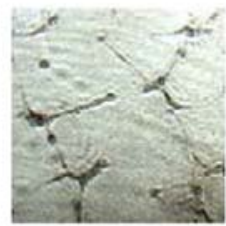

$10 \mu \mathrm{M}$

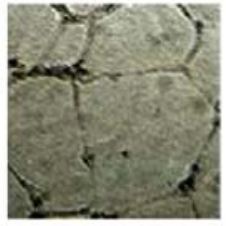

$5 \mu \mathrm{M}$

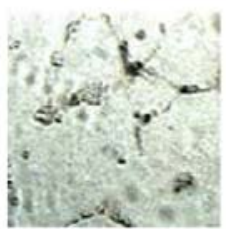

$20 \mu \mathrm{M}$
Figure 2. The effect of gallic acid (GA) on VEGF expression and in vitro angiogenesis in ovarian cancer cell lines. (A) GA inhibited VEGF secretion in OVCAR-3 and A2780/CP70 cells in a dose-dependent manner. The inhibitory effects on A2780/CP70 cells treated with 10 and $20 \mu \mathrm{M}$ GA were different from the control but they were not significant $(\mathrm{P}=0.116$ and 0.095 , respectively). Data represents the means $\pm \mathrm{SE}$ from three independent experiments. All data were analyzed by one-way ANOVA analysis followed by Dunnett's test. " $\mathrm{P}<0.05$ as compared to the control; ${ }^{* *} \mathrm{P}<0.01$ as compared to the control. (B) GA inhibits in vitro angiogenesis in OVCAR-3 cancer cells.

Notably, GA did not have a significant inhibitory effect on the normal cell line (IOSE-364) at $40 \mu \mathrm{M}$. This result indicates that the inhibitory effects of GA on normal ovarian cells were less than that on the ovarian cancer cells. Therefore, GA selectively inhibits cancer cells while having significantly weaker inhibitory effects on normal ovarian cells.

Many polyphenols have poor bioavailability, with about a 100-1,000 $\mathrm{nM}$ concentration in human serum. However, analyses of the bioavailability of polyphenols in humans reveal that GA performs better than other polyphenols (27). A concentration of $\sim 8-10 \mu \mathrm{M}$ of GA was detected in the serum of healthy volunteers, after oral intake of a combination of a dietary herbal supplement and $800 \mathrm{mg} \mathrm{GA}$ (28). The GA concentration found in this study is very close to therapeutic concentrations. A slight decrease in cell viability at $10 \mu \mathrm{M} \mathrm{GA}$ treatment was also observed, although this decrease did not reach statistical significance.

VEGF is the best studied and the most potent pro-angiogenic factor known $(29,30)$. For the purpose of angio-prevention, levels of VEGF were examined. As shown in Fig. 2A, VEGF expression in the A2780/CP70 cells and OVCAR-3 cells with $40 \mu \mathrm{M}$ GA treatment was significantly inhibited to 24.05 
A
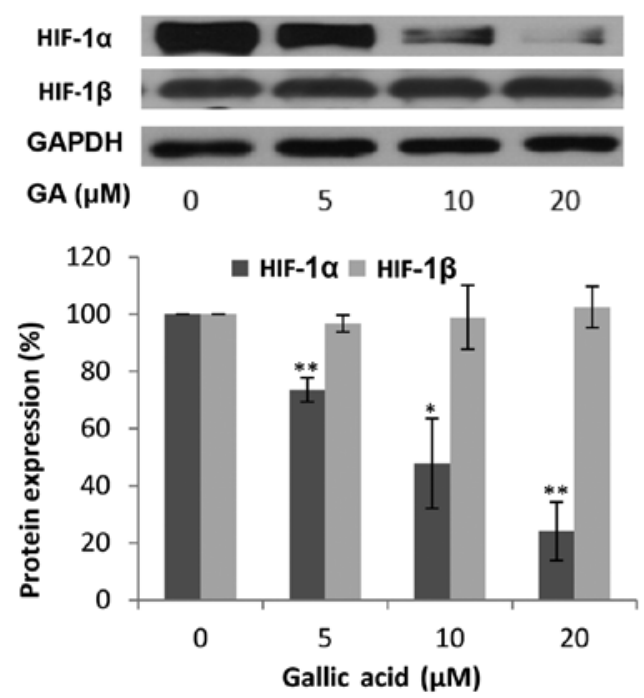

B

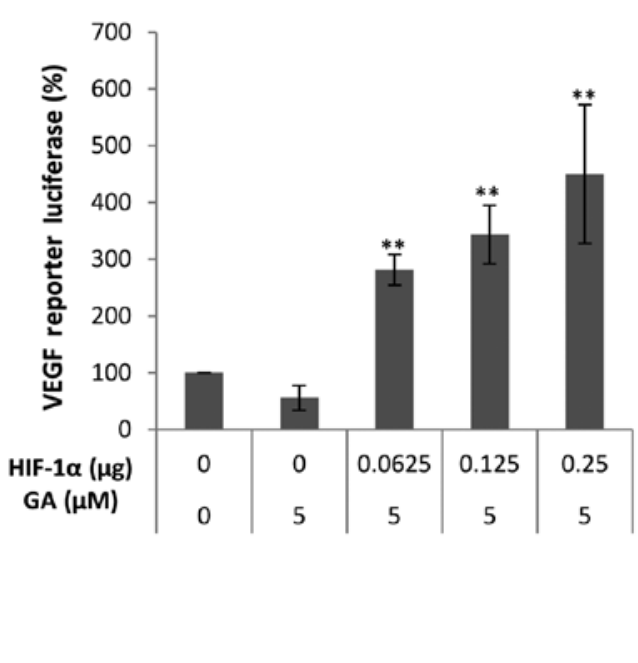

Figure 3. The effect of gallic acid (GA) on HIF-1 $\alpha$ and HIF-1 $\beta$ protein expression in OVCAR-3 cells and luciferase assay after transfection with VEGF luciferase reporter and HIF-1 $\alpha$ plasmids. (A) GA decreases HIF-1 $\alpha$ protein expression. Data represents mean \pm SE from 4 independent experiment. (B) HIF-1 $\alpha$ mediates the inhibitory effect by GA on VEGF transcriptional activation. Data represents means $\pm \mathrm{SE}$ from 6 independent experiments. ${ }^{* *} \mathrm{P}<0.01$ as compared to the control.

and $27.12 \%$, respectively. The inhibitory effect on OVCAR-3 cells increased significantly when the concentrations were $>5 \mu \mathrm{M}$ while for A2780/CP70 cells the concentrations were $>40 \mu \mathrm{M}$. Levels of VEGF excreted by OVCAR-3 cancer cells were inhibited to $82.75,79.22,68.88$, and $27.12 \%$ by $5,10,20$, and $40 \mu \mathrm{M}$ GA treatments, respectively.

The inhibitory effect of GA on the OVCAR-3 cells was more pronounced than that on the A2780/CP70 cells. As shown in Fig. 2A, the inhibitory effects on A2780/CP70 cells treated with 10 and $20 \mu \mathrm{M}$ GA were different from the control but they were not significant. This may be due to the lack of functional DNA mismatch repair of A2780/CP70 cells, which hampers the inhibitory effect of GA (31).

Since 8 to $10 \mu \mathrm{M}$ of GA in the blood is attainable in humans following a plant-rich diet, our research suggests that GA can directly inhibit VEGF secretion of ovarian cancer cells at physiologically relevant concentrations. This is an exciting result which indicates that GA may have legitimate potential in treating cancer patients in the clinic.

GA inhibits in vitro angiogenesis induced by OVCAR-3 in ovarian cancer cells. Angiogenesis, the formation of new blood vessels, is essential for tumor development and subsequent growth, invasion and metastasis. Suppressed expression of VEGF by kaempferol and chaetoglobosin $\mathrm{K}$ has been shown to inhibit in vitro angiogenesis in our previous research $(17,32)$. GA may have a similar effect of inhibiting tube formation by HUVECs induced by VEGF. Therefore, we investigated the effect of GA on in vitro tube formation by HUVECs induced by the culture medium of ovarian cancer cells treated with different concentrations of GA. We found that the culture media conditioned by OVCAR-3 ovarian cancer cells promoted in vitro angiogenesis and presented a well-established network of HUVECs (Fig. 2B). Following treatment with increasing concentrations of GA treatment, the network was scattered down and HUVECs gradually lost their ability to form tube structures. A 20- $\mu \mathrm{M}$ GA treatment completely destroyed the network structure, and HUVECs were presented as mostly individual clumps. Similar to other compounds in our earlier research, GA inhibits in vitro angiogenesis through suppression of VEGF expression.

GA inhibits VEGF production through downregulation of $H I F-1 \alpha$ expression. It has been well established that hypoxia stimulates transcriptional activation of VEGF through induction of HIF-1 $\alpha$, and HIF- $1 \alpha$ is considered a primary regulator of VEGF production. Thus, we first examined the influence of GA treatment on HIF-1 $\alpha$ expression. It is generally thought that HIF- $1 \alpha$ is regulated mainly by low oxygen or hypoxia as its name indicates. However, in concordance with our previous findings, HIF-1 $\alpha$ is highly expressed in normoxic conditions in ovarian cancer cells (32). As expected, the protein levels of HIF-1 $\alpha$ in the OVCAR-3 cancer cell line were markedly decreased with higher concentrations of GA. At $20 \mu \mathrm{M}$, the protein levels of HIF-1 $\alpha$ were $23.48 \%$ of the levels of HIF-1 $\beta$. This means that GA effectively decreased the protein expression of HIF-1 $\alpha$. These results suggest that HIF-1 $\alpha$ may be involved in the inhibitory mechanism of VEGF production by GA treatment. To confirm that HIF-1 $\alpha$ expression is not only regulated by GA treatment but also plays a role in the inhibition of VEGF secretion by GA, OVCAR-3 cells were transfected with the VEGF-promoter reporter, together with HIF-1 $\alpha$ plasmids. As shown in Fig. 3B, this inhibition of VEGF was significantly reversed by forced expression of the HIF-1 $\alpha$ protein. The higher the expression of HIF-1 $\alpha$, the higher the increase in the expression of the VEGF reporter. These results demonstrated that GA inhibits VEGF production through a HIF-1 $\alpha$-dependent pathway.

The transcription factor HIF-1 consists of two subunits, HIF-1 $\alpha$ and HIF-1 $\beta$. Research has shown that HIF-1 $\beta$ may be 
A
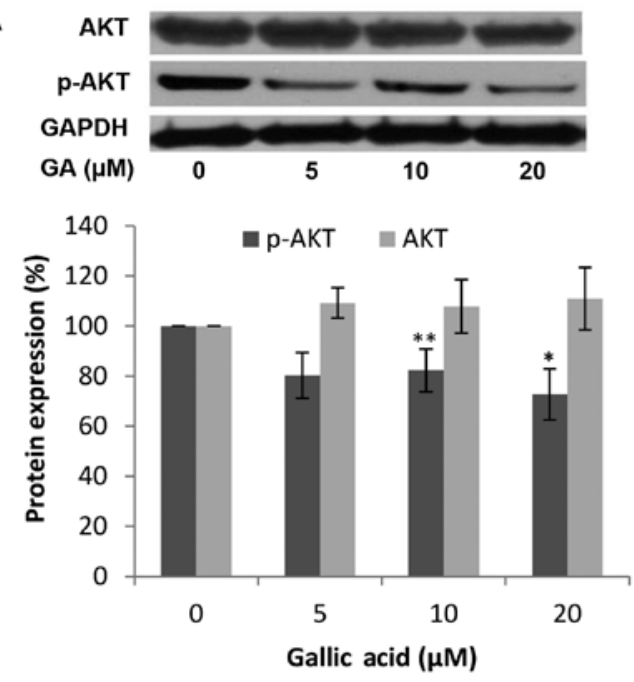

B

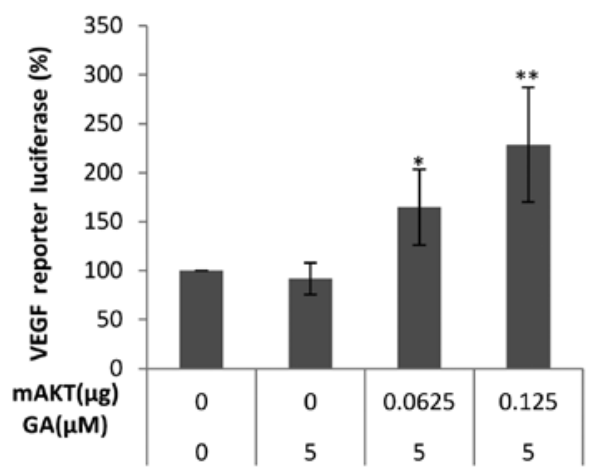

C

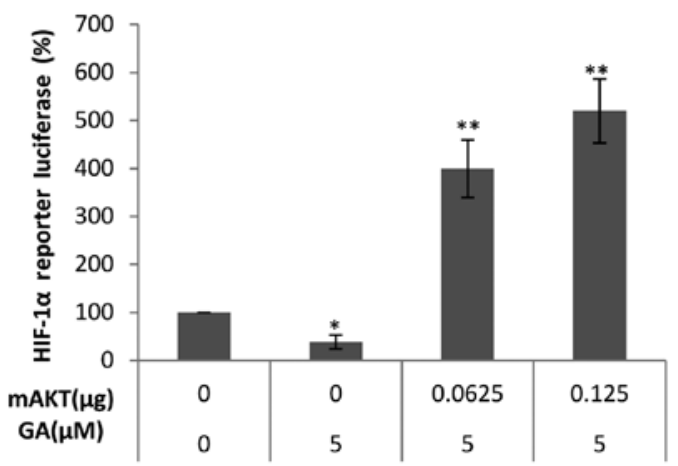

Figure 4. The effect of gallic acid (GA) on p-AKT and AKT protein expression in OVCAR-3 cells and luciferase assay after transfection with mAKT plasmids and VEGF luciferase reporter or HIF-1 $\alpha$ luciferase reporter. (A) GA decreases p-AKT protein expression in OVCAR-3 cells. Data represents mean \pm SE from 5 independent experiment. (B) $\mathrm{mAKT}$ mediates the inhibitory effects of GA on VEGF expression in ovarian cancer cells. Data represents mean $\pm \mathrm{SE}$ from 8 independent experiment. (C) mAKT mediates the inhibitory effects of GA on HIF-1 $\alpha$ expression in ovarian cancer cells. Data represents mean \pm SE from 4 independent experiments. ${ }^{*} \mathrm{P}<0.05$ as compared to the control; ${ }^{* *} \mathrm{P}<0.01$ as compared to the control.

regulated through an HIF-1 $\alpha$-dependent pathway (33). Thus, the protein levels of HIF-1 $\beta$ were also investigated. As shown in Fig. 3A, GA did not have a significant effect on the expression of HIF-1 $\beta$. As generally regarded, HIF-1 $\beta$ is constitutively expressed in ovarian cancer cells. GA inhibits VEGF production through transcription factor, HIF-1, by reducing the expression of HIF-1 $\alpha$.
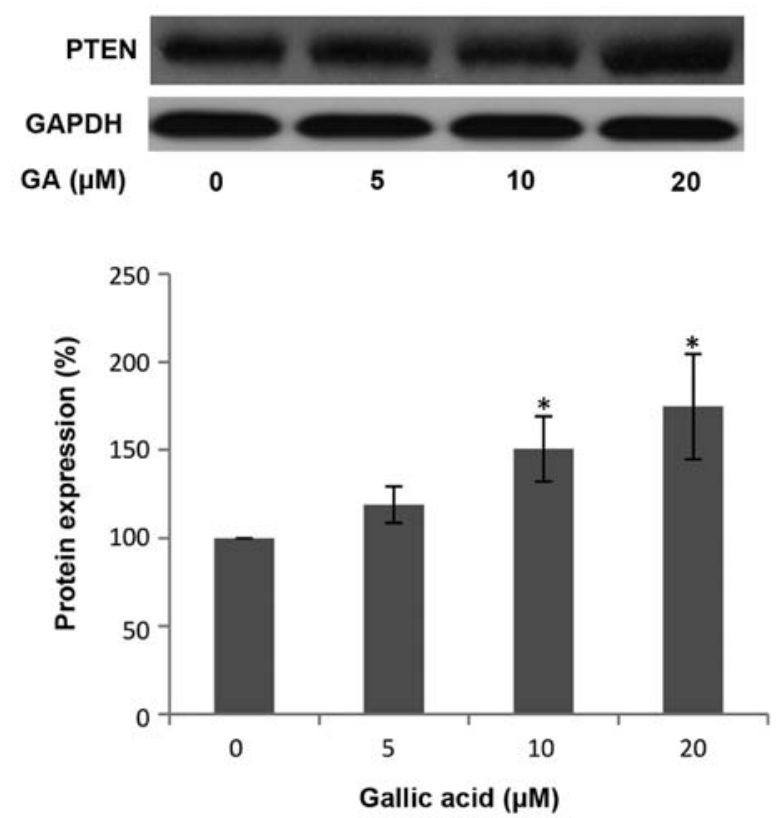

Figure 5. Gallic acid (GA) decreases p-AKT protein expression in OVCAR-3 cells. Data represents mean $\pm \mathrm{SE}$ from 5 independent experiments. ${ }^{*} \mathrm{P}<0.05$ as compared to the control.

GA inhibits HIF-1 $\alpha$ expression through blocking the phosphorylation of $A K T$. It is commonly recognized that the PI3K pathway plays an important role in the regulation of cell growth, motility, survival and metabolism, as well as angiogenesis. AKT, identified as an oncogene in the 1980's, serves as a central sensor in the PI3K pathway and represents an attractive therapeutic target since multiple signaling components converge in AKT (34). To check whether the inhibition of the expression of HIF-1 $\alpha$ and VEGF protein by GA is mediated by the AKT pathway, we first examined the levels of AKT and p-AKT protein after GA $(0,5,10$ and $20 \mu \mathrm{M})$ treatment. As shown in Fig. 4A, the protein levels of p-AKT in the OVCAR-3 cancer cell line were decreased with higher concentrations of GA while no significant change in the protein levels of AKT was found. These results demonstrate that GA inhibits the phosphorylation of AKT. To show that the activation of AKT plays a role in the inhibition of HIF-1 $\alpha$ and VEGF secretion by GA, OVCAR-3 cells were transfected with the HIF-1 $\alpha$ promoter reporter, together with the mAKT plasmids. As shown in Fig. 4B and C, the inhibition of HIF-1 $\alpha$ and VEGF was significantly reversed by forced expression of the mAKT protein, and the higher the expression of $\mathrm{mAKT}$, the higher the expression of the HIF-1 $\alpha$ reporter and VEGF reporter. These results demonstrate that GA inhibits HIF-1 $\alpha$ and VEGF expression through blocking the phosphorylation of AKT. The regulating effect of AKT on HIF-1 $\alpha$ or VEGF expression in ovarian cancer cells was also reported $(35,36)$. Research into how the PI3K/AKT/mTOR pathway affects the progression and tumorigenesis of ovarian cancer may lead to new therapies that will increase the survival of these patients (37). The inhibitory effect of GA on the PI3K/Akt pathway demonstrates great therapeutic potential for ovarian cancer.

GA upregulates PTEN expression in OVCAR-3 ovarian cancer cells. Phosphatase and tensin homolog deleted on 


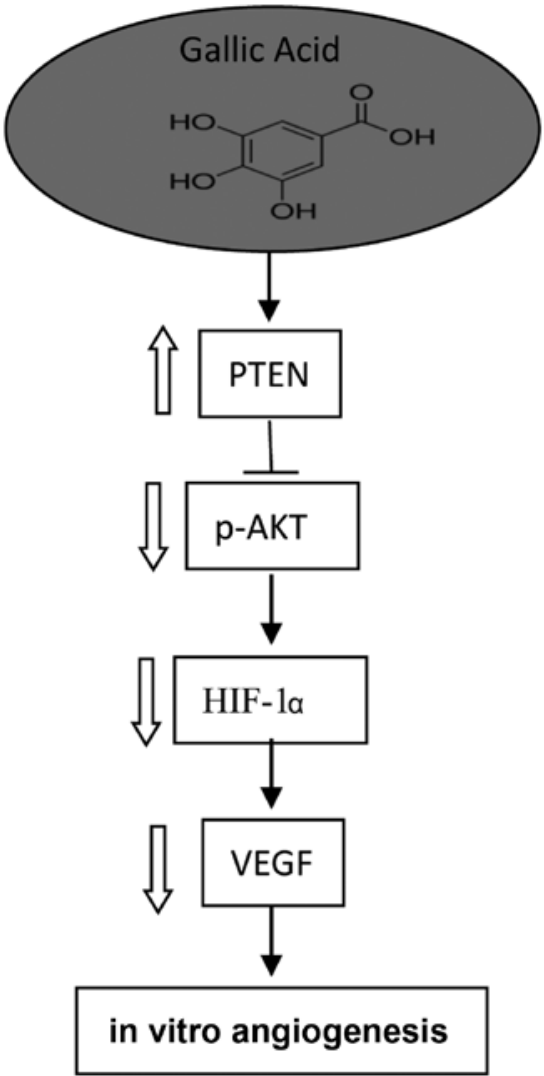

Figure 6. Newly proposed pathways for the effect of GA on angiogenesis in ovarian cancer cells

chromosome 10 (PTEN) is a tumor suppressor commonly mutated in many human cancers. PTEN hydrolyzes the 3-phosphate on PIP3 to generate PIP2 and negatively regulates PIP3-mediated signaling pathways. AKT is one of the most important downstream targets of PI3K. Therefore, PTEN can control HIF- $1 \alpha$ and VEGF expression through the PI3K/AKT pathway (38). To examine whether PTEN is involved in the inhibition of HIF-1 $\alpha$ and VEGF expression by GA, the level of PTEN protein was investigated by western blot analysis. As shown in Fig. 5, the protein levels of PTEN in the OVCAR-3 cancer cell line were increased following treatment with a high concentration of GA. This increase in PTEN protein expression indicates that GA may inhibit HIF-1 $\alpha$ and VEGF expression through upregulating PTEN protein.

In conclusion, we investigated the molecular mechanism of GA concerning its inhibition of VEGF expression and in vitro angiogenesis activity. In the present study, GA was found to directly inhibit VEGF secretion of ovarian cancer cells at physiologically relevant concentrations $(5 \mu \mathrm{M})$. These experiments demonstrate that GA has great potential in the prevention and therapy of ovarian cancer. To our knowledge, this is the first study that addresses the anti-angiogenesis effect of GA on ovarian cancer.

HIF-1, a transcription factor, can directly activate VEGF expression. Our research shows that GA inhibits VEGF production through the transcription factor, HIF-1 by markedly reducing the expression of HIF- $1 \alpha$. GA can inhibit the expression of VEGF at low concentrations possibly due to the strong inhibition of the expression of HIF-1 $\alpha$. Furthermore, the inhibitory effect of GA may be involved in the suppression of AKT phosphorylation and upregulation of PTEN expression. A mechanism/pathway for the inhibition of VEGF expression by GA in ovarian cancer cells is proposed (Fig. 6). These findings enhance our understanding of its mechanism of action and provide strong support for using this compound in future animal and clinical studies.

AKT is an important serine-threonine protein kinase and carries out various cellular functions such as angiogenesis, cell metabolism, cell survival/inhibition of apoptosis, and the cell cycle. The inhibition of AKT phosphorylation by GA may imply that GA induces various other cellular functions that require further study.

\section{Acknowledgements}

This research was supported by an NIH grant (5P20RR016477 and 8P20GM104434) from the National Center for Research Resources awarded to the West Virginia IDeA Network of Biomedical Research Excellence and the National Science Foundation (1003907), the West Virginia Higher Education Policy Commission/Division of Science Research. The authors also thank the financial support from Natural Science Foundation of Zhejiang Province (LY13C200013) and the Research and Development Fund of Zhejiang A \& F University (2012FR024).

\section{References}

1. Sánchez-González C, Ciudad CJ, Noé V and Izquierdo-Pulido M: Walnut polyphenol metabolites, urolithins $\mathrm{A}$ and $\mathrm{B}$, inhibit the expression of the prostate-specific antigen and the androgen receptor in prostate cancer cells. Food Funct 5: 2922-2930, 2014.

2. Lewandowska U, Owczarek K, Szewczyk K, Podsędek A, Koziołkiewicz M and Hrabec E: Influence of polyphenol extract from evening primrose (Oenothera paradoxa) seeds on human prostate and breast cancer cell lines. Postepy Hig Med Dosw (Online) 68: 110-118, 2014.

3. Stagos D, Amoutzias GD, Matakos A, Spyrou A, Tsatsakis AM and Kouretas D: Chemoprevention of liver cancer by plant polyphenols. Food Chem Toxicol 50: 2155-2170, 2012.

4. Di Domenico F, Foppoli C,Coccia R and Perluigi M: Antioxidants in cervical cancer: Chemopreventive and chemotherapeutic effects of polyphenols. Biochim Biophys Acta 1822: 737-747, 2012.

5. Abbas A, Patterson W III and Georgel PT: The epigenetic potentials of dietary polyphenols in prostate cancer management. Biochem Cell Biol 91: 361-368, 2013.

6. Haraguchi T, Kayashima T, Okazaki Y, Inoue J, Mineo S, Matsubara K, Sakaguchi E, Yanaka N and Kato N: Cecal succinate elevated by some dietary polyphenols may inhibit colon cancer cell proliferation and angiogenesis. J Agric Food Chem 62: 5589-5594, 2014.

7. Lall RK, Syed DN, Adhami VM, Khan MI and Mukhtar H: Dietary polyphenols in prevention and treatment of prostate cancer. Int J Mol Sci 16: 3350-3376, 2015.

8. Jemal A, Bray F, Center MM, Ferlay J, Ward E and Forman D: Global cancer statistics. CA Cancer J Clin 61: 69-90, 2011.

9. Siegel R, Miller KD and Jemal A: Cancer statistics, 2015. CA: A Cancer Journal for Clinicians 65: 5-29, 2015.

10. Vargas-Hernández VM, Moreno-Eutimio MA, AcostaAltamirano G and Vargas-Aguilar VM: Management of recurrent epithelial ovarian cancer. Gland Surg 3: 198-202, 2014.

11. Cohen JG, White M, Cruz A and Farias-Eisner R: In 2014, can we do better than CA125 in the early detection of ovarian cancer? World J Biol Chem 5: 286-300, 2014.

12. Kigawa J: New strategy for overcoming resistance to chemotherapy of ovarian cancer. Yonago Acta Med 56: 43-50, 2013.

13. Ott I and Gust R: Non platinum metal complexes as anti-cancer drugs. Arch Pharm (Weinheim) 340: 117-126, 2007. 
14. Ayyagari VN and Brard L: Bithionol inhibits ovarian cancer cell growth in vitro - studies on mechanism(s) of action. BMC Cancer 14: 61, 2014

15. Agarwal R and Kaye SB: Ovarian cancer: Strategies for overcoming resistance to chemotherapy. Nat Rev Cancer 3: 502-516, 2003.

16. Luo H, Jiang BH, King SM and Chen YC: Inhibition of cell growth and VEGF expression in ovarian cancer cells by flavonoids. Nutr Cancer 60: 800-809, 2008

17. Luo H, Rankin GO, Juliano N, Jiang BH and Chen YC: Kaempferol inhibits VEGF expression and in vitro angiogenesis through a novel ERK-NFкB-cMyc-p21 pathway. Food Chem 130: 321-328, 2012

18. Chen AY and Chen YC: A review of the dietary flavonoid, kaempferol on human health and cancer chemoprevention. Food Chem 138: 2099-2107, 2013.

19. Kuo CL, Lai KC, Ma YS, Weng SW, Lin JP and Chung JG: Gallic acid inhibits migration and invasion of SCC-4 human oral cancer cells through actions of NF- $\kappa \mathrm{B}$, Ras and matrix metalloproteinase-2 and -9. Oncol Rep 32: 355-361, 2014.

20. You BR, Kim SZ, Kim SH and Park WH: Gallic acid-induced lung cancer cell death is accompanied by ROS increase and glutathione depletion. Mol Cell Biochem 357: 295-303, 2011.

21. Cedó L, Castell-Auví A, Pallarès V, Macià A, Blay M, Ardévol A Motilva MJ and Pinent M: Gallic acid is an active component for the anticarcinogenic action of grape seed procyanidins in pancreatic cancer cells. Nutr Cancer 66: 88-96, 2014.

22. Lu Y, Jiang F, Jiang H, Wu K, Zheng X, Cai Y, Katakowski M, Chopp M and To SS: Gallic acid suppresses cell viability, proliferation, invasion and angiogenesis in human glioma cells. Eur J Pharmacol 641: 102-107, 2010.

23. Zhao B and Hu M: Gallic acid reduces cell viability, proliferation invasion and angiogenesis in human cervical cancer cells. Oncol Lett 6: 1749-1755, 2013

24. He Z, Li B, Rankin GO, Rojanasakul Y and Chen YC: Selecting bioactive phenolic compounds as potential agents to inhibit proliferation and VEGF expression in human ovarian cancer cells. Oncol Lett 9: 1444-1450, 2015.

25. Jafari S, Saeidnia S and Abdollahi M: Role of natural phenolic compounds in cancer chemoprevention via regulation of the cell cycle. Curr Pharm Biotechnol 15: 409-421, 2014.

26. Carocho M and Ferreira IC: The role of phenolic compounds in the fight against cancer - a review. Anticancer Agents Med Chem 13: 1236-1258, 2013.
27. Manach C, Williamson G, Morand C, Scalbert A and Rémésy C: Bioavailability and bioefficacy of polyphenols in humans. I. Review of 97 bioavailability studies. Am J Clin Nutr 81 (Suppl 1): 230S-242S, 2005.

28. Roberts AT, Martin CK, Liu Z, Amen RJ, Woltering EA, Rood JC, Caruso MK, Yu Y, Xie H and Greenway FL: The safety and efficacy of a dietary herbal supplement and gallic acid for weight loss. J Med Food 10: 184-188, 2007.

29. Yamamizu K, Furuta S, Hamada Y, Yamashita A, Kuzumaki N, Narita M, Doi K, Katayama S, Nagase H, Yamashita JK, et al: $\kappa$ opioids inhibit tumor angiogenesis by suppressing VEGF signaling. Sci Rep 3: 3213, 2013.

30. Huang KF, Yang HY, Xing YM, Lin JS and Diao Y: Recombinant human kallistatin inhibits angiogenesis by blocking VEGF signaling pathway. J Cell Biochem 115: 575-584, 2014.

31. Strathdee G, MacKean MJ, Illand M and Brown R: A role for methylation of the hMLH1 promoter in loss of hMLH1 expression and drug resistance in ovarian cancer. Oncogene 18: 2335-2341, 1999

32. Luo H, Li B, Li Z, Cutler SJ, Rankin GO and Chen YC: Chaetoglobosin $\mathrm{K}$ inhibits tumor angiogenesis through downregulation of vascular epithelial growth factor-binding hypoxia-inducible factor 1 $\alpha$. Anticancer Drugs 24: 715-724, 2013

33. MandlM,Kapeller B,LieberR and Macfelda K:Hypoxia-inducible factor-1 $\beta$ (HIF-1 $\beta)$ is upregulated in a HIF-1 $\alpha$-dependent manner in 518A2 human melanoma cells under hypoxic conditions. Biochem Biophys Res Commun 434: 166-172, 2013.

34. Li H,Zeng J and Shen K: PI3K/AKT/mTOR signaling pathway as a therapeutic target for ovarian cancer. Arch Gynecol Obstet 290: 1067-1078, 2014

35. Park ST, Kim BR, Park SH, Lee JH, Lee EJ, Lee SH and Rho SB: Suppression of VEGF expression through interruption of the HIF $1 \alpha$ and Akt signaling cascade modulates the anti angiogenic activity of DAPK in ovarian carcinoma cells. Oncol Rep 31 : 1021-1029, 2014.

36. Mao $\mathrm{Y}, \mathrm{Xu}$ J, Song $\mathrm{G}$, Zhang $\mathrm{N}$ and $\mathrm{Yin} \mathrm{H}$ : Twist2 promotes ovarian cancer cell survival through activation of Akt. Oncol Lett 6: 169-174, 2013.

37. Dobbin ZC and Landen CN: The importance of the PI3K/AKT/mTOR pathway in the progression of ovarian cancer. Int J Mol Sci 14: 8213-8227, 2013.

38. Jiang BH and Liu LZ: PI3K/PTEN signaling in angiogenesis and tumorigenesis. Adv Cancer Res 102: 19-65, 2009. 